\title{
Stability analysis of an industrial salinity gradient solar pond
}

2 M. Montalà 1,2 , J. L. Cortina ${ }^{1,2,3}$, A. Akbarzadeh ${ }^{4}$, C. Valderrama ${ }^{1,2}$

$3{ }^{1}$ Chemical Engineering Department, UPC-BarcelonaTECH, C/ Eduard Maristany, 10-14 (Campus

4 Diagonal-Besòs), 08930 Barcelona, Spain

52 Barcelona Research Center for Multiscale Science and Engineering, C/ Eduard Maristany, 10-14

6 (Campus Diagonal-Besòs), 08930 Barcelona, Spain

73 Water Technology Center CETaqua, Barcelona, Spain

${ }^{4}$ School of Aerospace, Mechanical and Manufacturing Engineering, RMIT University, Australia

*Correspondence should be addressed to: César Valderrama

Departament d'Enginyeria Química, Universitat Politècnica de Catalunya-Barcelona TECH

C/ Eduard Maristany, 10-14 (Campus Diagonal-Besòs), 08930 Barcelona, Spain

Tel.: 93 4011818, Fax.: 934015814

Email: cesar.alberto.valderrama@upc.edu

\section{Abstract}

In this study, an assessment of salinity gradient stability of an industrial solar pond during two operation seasons (2014 and 2105) is presented. An industrial solar pond was constructed to supply a lowtemperature heat (up to $60^{\circ} \mathrm{C}$ ) to achieve the temperature requirements of the flotation stage in a mineral processing plant (Solvay Minerales in Granada (Spain)). Along the first season, the salinity gradient was considered technically destroyed in April 2015 as the height to the upper convective zone increases from $0.3 \mathrm{~m}$ in July 2014 to $0.8 \mathrm{~m}$. Two different methodologies based on the stratification principle were adapted and used in order to evaluate the salinity gradient stability. The boundaries of the salinity gradient appeared as the main source of instability. In the upper zone it is associated with the environmental parameters (e.g., rain and wind) that affect the upper convective zone and the upper 
layers of the non-convective zone that subsequently transmit the instability to the lower layers. In the bottom zone it is caused by operation parameters, such as the heat extraction or the addition of salt. Both methodologies provided similar predictive capability of stability results. However, the results provided by the stability analysis using the thermal and salinity expansion coefficients are a more useful tool in the control of the salinity gradient for solar pond technology.

Keywords: solar energy; industrial solar pond; salinity gradient; stability analysis; mineral flotation

\section{Introduction}

The stability of salinity gradient is crucial to ensure the proper operation of solar pond technology. Experimental studies in industrial or prototype solar ponds are difficult to be found, and most of the studies reported in the literature are theoretical models (Husain et al., 2012; El Mansouri et al., 2018). Only in the solar pond of El Paso, Texas, a stability analysis was reported (Lu et al., 2004). The concept of stability is generally related with salinity/temperature stratification. Stratification in water is produced when masses of water at different properties, such as salinity, density or temperature, form different layers without mixing.

A solar pond is a system composed by three main zones: the upper convective zone (UCZ), the nonconvective zone (NCZ) and the lower convective zone (LCZ). The upper and lower zones of the system are characterized to transfer heat by convection. Convective heat transfer implies water movements; as a consequence, stratification is not possible. On the other hand, the NCZ is the only part of the system where no convective movements are found (Valderrama et al., 2016). When the solar pond is filled, the $\mathrm{NCZ}$ is created overlapping layers with different salt concentrations. As a result, the NCZ of a solar pond should be initially stratified, a stability analysis in this region provides information about the initial stability and the evolution of the different layers (Zangrando,1980). The heat stored in the LCZ can be used as a heat source for the heating of buildings, power production and industrial processing and more recently 
51 the addition of heat from external sources (Alcaraz et al., 2018c; Ganguly et al., 2018a) has been

$$
S M N=\frac{\partial S_{a} / \partial z}{\partial S_{j} / \partial z}
$$

64 where, $\frac{\partial S_{a}}{\partial z}$ is the actual salinity gradient, in percentage, and $\frac{\partial S_{j}}{\partial z}$ is the theoretical salinity gradient, also in explored. Also in recent year a great effort has been made in optimizing the overall performance of solar pond technology (Kumar et al., 2018; Ganguly et al., 2018b).

The solar pond of El Paso, Texas, has become a worldwide reference facility for solar pond technology. From its construction and operation in 1985 different publications with a large amount of data have been published. Leblanc et al. (2011) and Lu et al. (2004) also reported a stability analysis. The study was based in the NCZ and the boundary regions, NCZ-UCZ and NCZ-LCZ. The internal stability was quantified through the Stability Margin Number (SMN), which may be defined as the ratio of the measured stability coefficient to the calculated stability coefficient required to satisfy the dynamic stability criterion for the temperature profile of the solar pond at height $z$ within the NCZ. The solar pond of El Paso was the first system that included the stability analysis of the NCZ as a routine procedure in its operation and control. The difficulty to find in literature some reliable models resulted in the development of a specific methodology for this system (Xu et al., 1987). The SMN is defined as described by Eq. 1:

percentage, necessary to satisfy the stability criterion for the temperature profile of the solar pond at height $z$ within the NCZ. In principle, the SMN should be higher that 1 to ensure the stability of the system. However, it is also reported that when the SMN is lower than 1.6 the gradient may be degraded.

The main problem with the model suggested in the El Paso solar pond is that the methodology to determine $\frac{\partial s_{j}}{\partial z}$ is not specified.

Alenezi (2012) described in detail a theoretical model to analyze the stability of a solar pond. The work was based on the idea that the minimum requirement to keep the stability in the solar pond is that the 
density in the gradient zone should increase downward to prevent the different layers of the NCZ from mixing and consequently to prevent the salinity gradient to be degraded.

The author pointed out the significant relevance of the solar pond filling process, if the salinity gradient is not perfectly implemented during this process, the stability of the NCZ will be rapidly affected and, consequently, it is highly probable to identify the degradation of the gradient after a short period of operation.

Two different stabilities are identified and described in Alenezi (2012), static and dynamic stability. Basically, static stability only considers the internal situation of the system (stratification), since it identifies the vertical convection movements. Notwithstanding a solar pond can also be affected by external disturbance factors, especially by environmental factors such as rain or wind; this may result in an oscillatory movement of the surface of the system, if these waves arrive to the NCZ, the different layers would be mixed. Dynamic stability provides information about all these effects.

As for the static stability, the salt concentration should increase downward; in this case, the lower layers have a higher salt concentration than the upper ones. This situation is called as positive gradient. The opposite situation, salt concentration decreasing downward, would be called negative gradient. If a negative gradient dominates the system, the salinity gradient will be destroyed or at least the operation of the solar pond reduced, which will result in a significant reduction in efficiency (Alenezi, 2012).

These effects are studied to predict the static stability of a solar pond. With all said, it is known that the salt concentration value at some point of the NCZ should be higher than the point immediately above to avoid vertical convection in the zone. Thus, the stability condition suggested is defined as follows by Eq. 2. (Alenezi, 2012):

$$
\alpha \frac{\partial T}{\partial x} \leq \beta \frac{\partial S}{\partial x}
$$


93 where, $\frac{\partial T}{\partial x}$ is the temperature gradient with depth $(\mathrm{x}), \frac{\partial S}{\partial x}$ is the salinity gradient with depth $(\mathrm{x}), \alpha$ is the 94 thermal expansion coefficient and $\beta$ is the salinity expansion coefficient.

95 The density change with depth needs to satisfy Eq. 3, if the system is stable:

$\frac{\partial \rho}{\partial x}=\alpha \frac{\partial T}{\partial x}+\beta \frac{\partial S}{\partial x}>0$

Alenezi (2012) establishes also a relation between the saline, $\left(R_{S}\right)$, and thermal, $\left(R_{T}\right)$, Rayleigh numbers, thermal, $(\Delta T)$, and saline, $(\Delta S)$, gradients and coefficients of thermal, $(\alpha)$, and saline, $(\beta)$, expansion. Thus, equation 4 provides information of the stability behavior.

$R_{\rho}=\frac{R_{S}}{R_{T}}=\frac{\beta \Delta S}{\alpha \Delta T}$

Liu et al. (2015) and Ouni et al. (2003) used the previous methodology to numerically simulate a trapezoidal solar pond of prototype dimensions $(2.4 \mathrm{~m} \times 2.4 \mathrm{~m}$ at surface and $1 \mathrm{~m} \times 1 \mathrm{~m}$ at the bottom) and to model a salinity gradient solar pond (SGSP) in the south of Tunisia, respectively.

Talley et al. (2011) defined the static stability for seawater as a formal measure of the tendency of water column to overturn. The authors related the static stability with the stratification, the higher is the stratification the higher the stability. A layer of water is stable if a parcel of water that is moved adiabatically is capable to return to its original position. This capacity depends on the density difference between the layer and the immediately above and below layers. Thus, the static stability, $(E)$, of a layer is defined in Eq. 5:

$E=-\left(\frac{1}{\rho}\right) \frac{\partial \rho}{\partial x}$

where $\rho$ is in situ density, $\partial \rho$ the density variation with depth $\partial x$. If $E$ is positive, the system would be stable, if 0 , the system would be neutral and if negative, the system would be unstable. 
112 Except for the case of El Paso solar pond (USA), which developed a specific methodology to study the

113 stability of the system, the other studies focused on theoretical analyzes of the stability of a solar pond,

114 some of them tested with numerical simulation approaches, but none of them were validated with operation data from an industrial solar pond. Two different methodologies based on the stratification principle were adapted and used in order to evaluate the stability of an industrial solar pond $\left(500 \mathrm{~m}^{2}\right)$ during two operation seasons (2014 and 2105). The analysis of construction, operation and efficiency of this $500-\mathrm{m}^{2}$ industrial solar pond has been previously reported (Alcaraz et al., 2018a,b) and stability has been identified as the main issue from the point of view of the operation. The rationality of the analysis is the need to develop a methodology for assessing the stability of the salinity gradient using the operation data of the Granada solar pond.

\section{Methodology}

Although the stability of a solar pond is a key parameter to ensure proper functioning, most studies on salinity gradient solar ponds have not reported the stability analysis due to the complexity in determining this parameter. The stability cannot be directly measured from the sensors data installed for solar pond performance monitoring and the procedure to be determined is, in general, quite complex. In that context, in most of the solar pond the temperature and density gradients, which can be directly and easily measured, are used to control the different zones of the system.

\subsection{Evolution of the salinity gradient in the Granada Solar Pond}

The solar pond in Granada started its operation in July 2014 as was described by Alcaraz et al. (2018a). The degradation of the salinity gradient was detected by the density profile monitoring as the height to the UCZ increases from $0.3 \mathrm{~m}$ in July 2014 to $0.8 \mathrm{~m}$ in April 2015. Although the same trend was observed in the evolution of the temperature profile, the average monthly temperature of the LCZ not decreased below $40^{\circ} \mathrm{C}$. For the second, season, in April 2015 , the salinity gradient was considered to be technically 


$$
E=-\left(\frac{1}{\rho}\right) \frac{\Delta \rho}{\Delta x}
$$

158 If the parameter $E$ is positive, the system would be stable, if zero, neutral and if negative, unstable.

159 In addition, the methodology suggested by Alenezi (2012) is also considered in this analysis. The stability condition is expressed through the Eq. 7: 
$\alpha \frac{\partial T}{\partial x} \leq \beta \frac{\partial S}{\partial x}$

161 Which can be also expressed as:

$\alpha \frac{\Delta T}{\Delta x} \leq \beta \frac{\Delta S}{\Delta x}$

162 Once the coefficients of thermal and salinity expansion are calculated (see Appendix 1), the equation 7 is plotted for each depth over time to elucidate the evolution of each parameter and identify where and when the instabilities occur.

Both methodologies are based on the same principle, stratification as a synonym of stability. However, the use of different methods provides a broader picture of the stability of the system and helps to understand where and when the gradient starts the degradation process.

\section{Results and discussion}

In this section the initial stability of the solar pond at the beginning of each operation season in the

172 Granada solar pond and its evolution along each season are reported. As stability analyses of industrial

173 solar ponds in operation are not found in literature, the stability analysis of the Martorell pilot plant solar

174 pond $\left(50 \mathrm{~m}^{2}\right)$ was also performed (data not shown). Although the solar pond installed in Martorell was of a pilot scale (Valderrama et al., 2011; Bernard et al., 2013), the salinity gradient never degraded during its useful life (Alcaraz et al., 2016; 2018c), therefore it was considered a good example of successful operation and a reference to test the proposed methodology.

\subsection{First operation season}

179 In this subsection the stability of the first operation season is deeply analyzed. Figure 1 and 2 contained 180 the analysis of stability suggested by Talley et al. (2011). In Figure 1, the stability (E) is plotted as a 181 function of the depth of the salinity gradient (NCZ), the different lines represent the stability profile for each depth. 


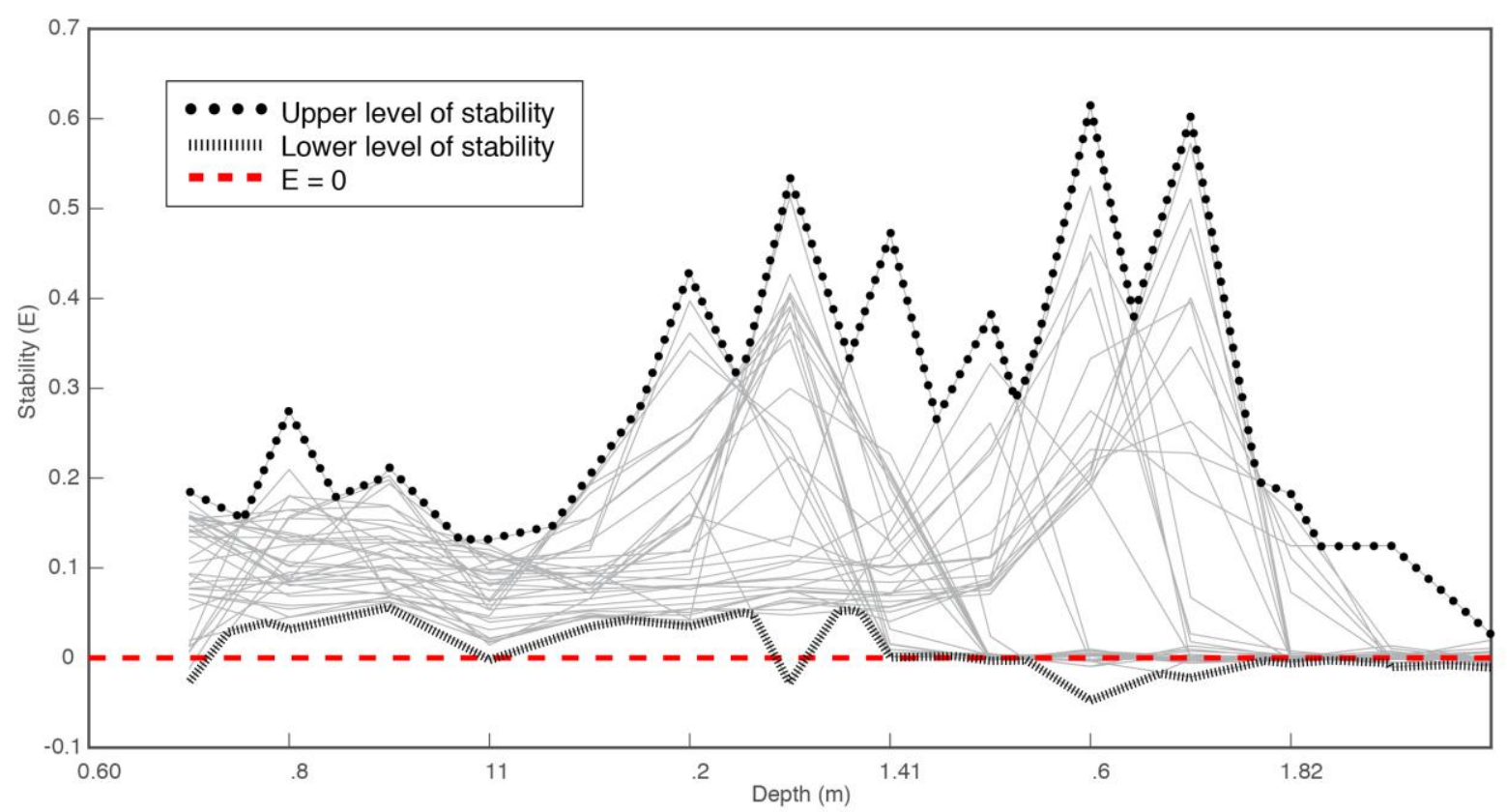

Figure 1. Variation of the Stability profile $(E)$ as a function of solar pond depth $(\mathrm{m})$ (from the bottom) along first operation season in Granada solar pond using the methodology described by Talley et al. (2011).

As can be seen in Figure 1, no significant instabilities has been identified. However, there are some points that tend to be neutral $(E=0)$ especially from depths greater than $1.3 \mathrm{~m}$ from the bottom. It is possible to identify periods of small instabilities in some points, $0.7,1.3,1.6,1.7$ and $1.9 \mathrm{~m}$ from the bottom. Along these periods the $E$ parameter become negative. However, it is not possible to identify when these instabilities occurred and if the system was able to recover stability in the next measurement or not. In this way, Figure 2 plots the same data but represented in a completely different way. In this case, the evolution of stability, $E$, at each depth can be easily identified along the operation season. This figure is useful to understand when the points (depths) mentioned above began to be unstable. 


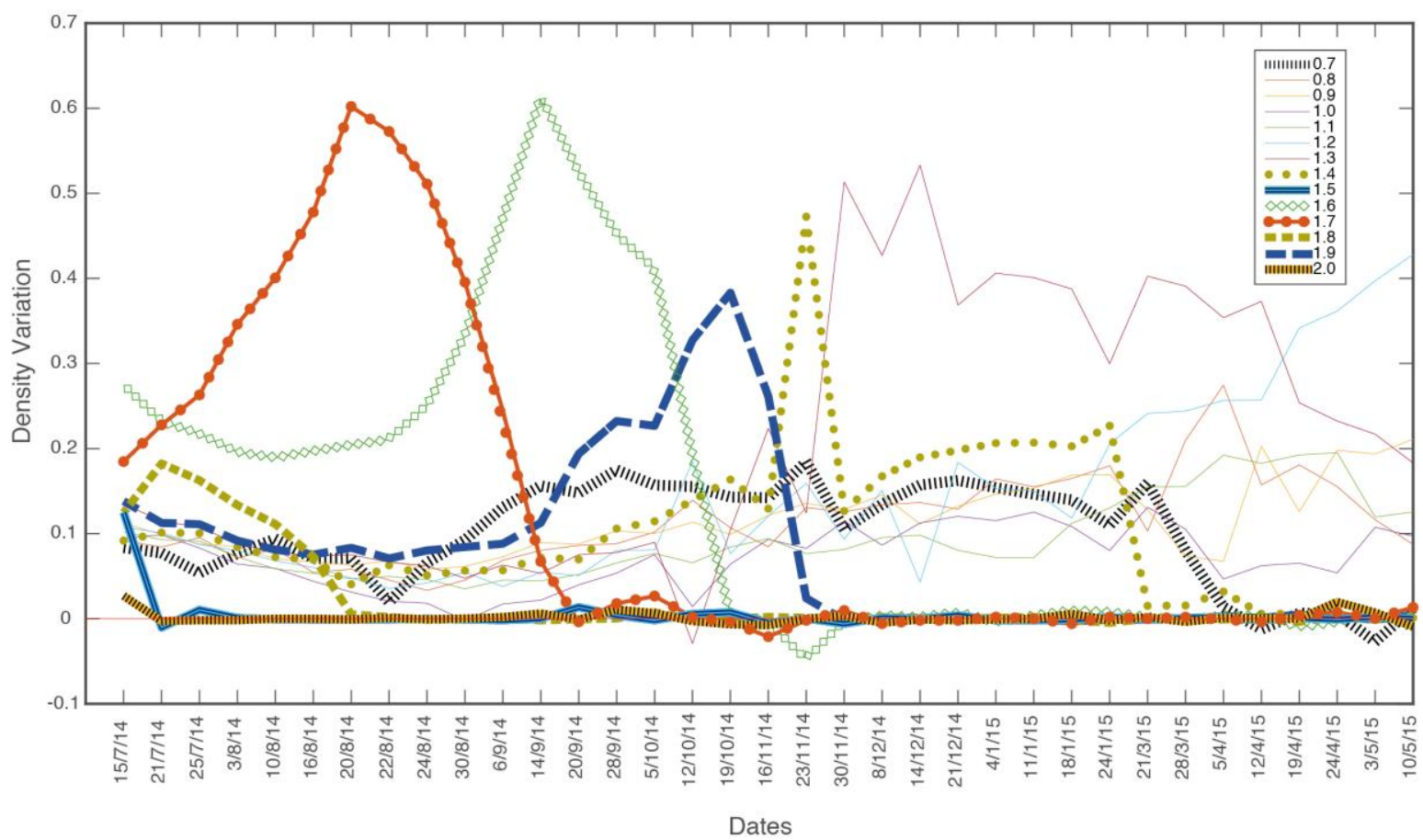

Figure 2. Stability evolution for different depth $(\mathrm{m})$ from the bottom along first operation season in Granada Solar Pond using the methodology described by Talley et al. (2011).

Initially, the system was clearly stable. However, at $2 \mathrm{~m}$ from the bottom, $E$ quickly (only 5 days after starting the operation) decreases to 0 , the neutral situation. This situation is transmitted to the lower layers of the NCZ. At $1.9 \mathrm{~m}$ from the bottom a slightly unstable situation is detected on $21^{\text {st }}$ July 2014 . However, the system was stable again on $26^{\text {th }}$ July. The following measures at this point resulted in an unstable situation. The system was not capable to recover again the stability. One month later, on $20^{\text {th }}$ August 2014, the neutral situation is also detected at $1.8 \mathrm{~m}$ from the bottom; once an unstable situation is generated, the system cannot recover its stability. After one month, on $20^{\text {th }}$ September 2014 , the same pattern is detected at $1.7 \mathrm{~m}$ from the bottom, on $8^{\text {th }}$ October 2014 ; the layer located at $1.6 \mathrm{~m}$ from the bottom also became neutral. Later, at 1.5 and $1.4 \mathrm{~m}$ from the bottom, the same trend was observed, on 30th November 2014 and $12^{\text {th }}$ April 2015, respectively.

A neutral situation is not desired because it is difficult to completely avoid convective movements under this scenario. The neutral trend began at the beginning of the first season of operation $2 \mathrm{~m}$ from the 
bottom. On average, the unstable situation needed about a month to be detected in the layer immediately below. However, it took almost five months to detect an unstable situation at $1.4 \mathrm{~m}$ from the bottom. On

213 the other hand, the layer located at $0.7 \mathrm{~m}$ from the bottom, which is the one in contact with the LCZ,

214 began to be unstable on April 6, 2015. At this point, the gradient was considered severely damaged.

215 The system is also analyzed using the coefficients of thermal and salinity expansion as described by 216 Alenezi (2012), according to this methodology $\beta \frac{\partial S}{\partial x}$ should be always higher than $\alpha \frac{\partial T}{\partial x}$. Figure 3 shows 217 the evolution of temperature and salinity in each recorded depth for the first season.
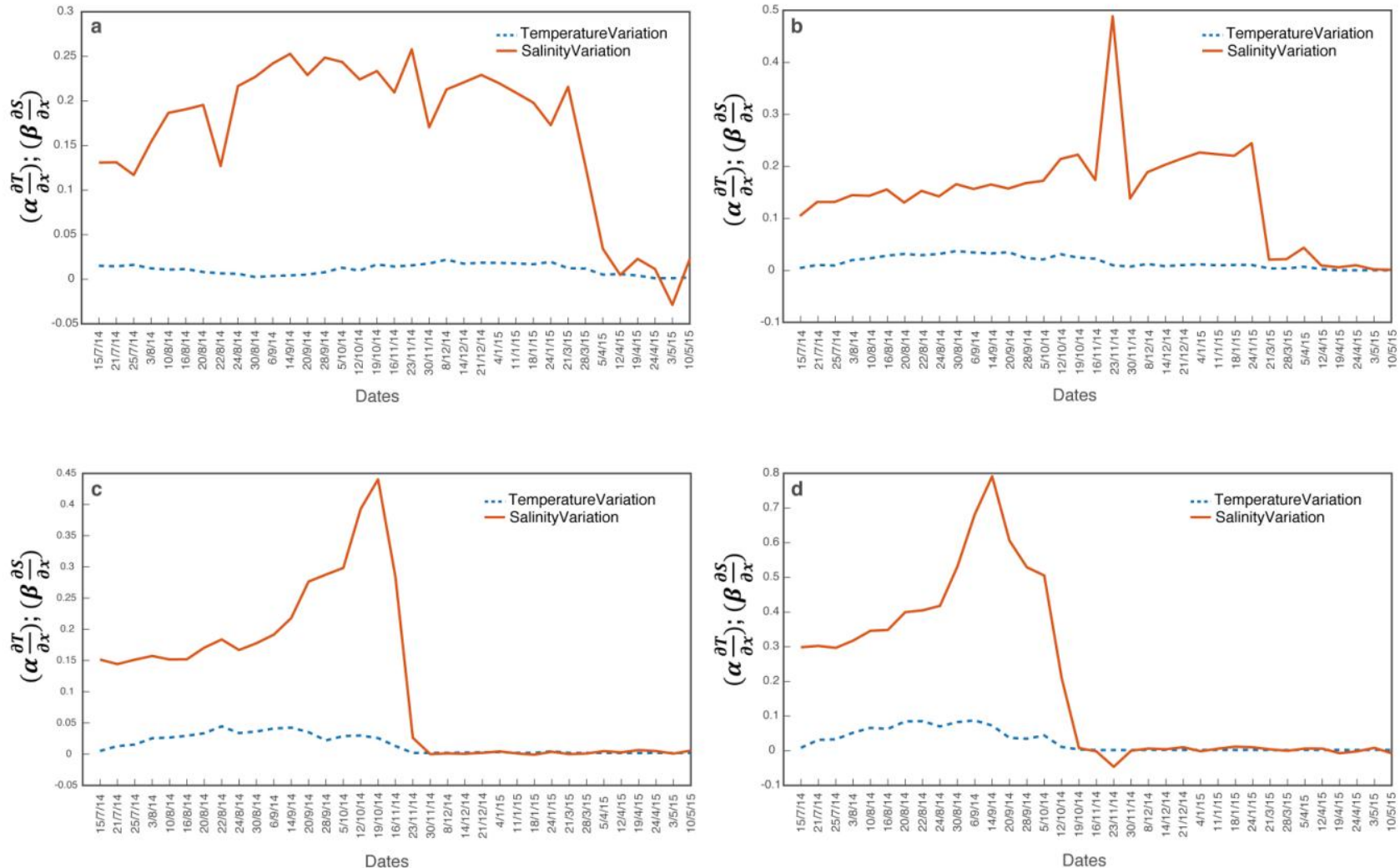

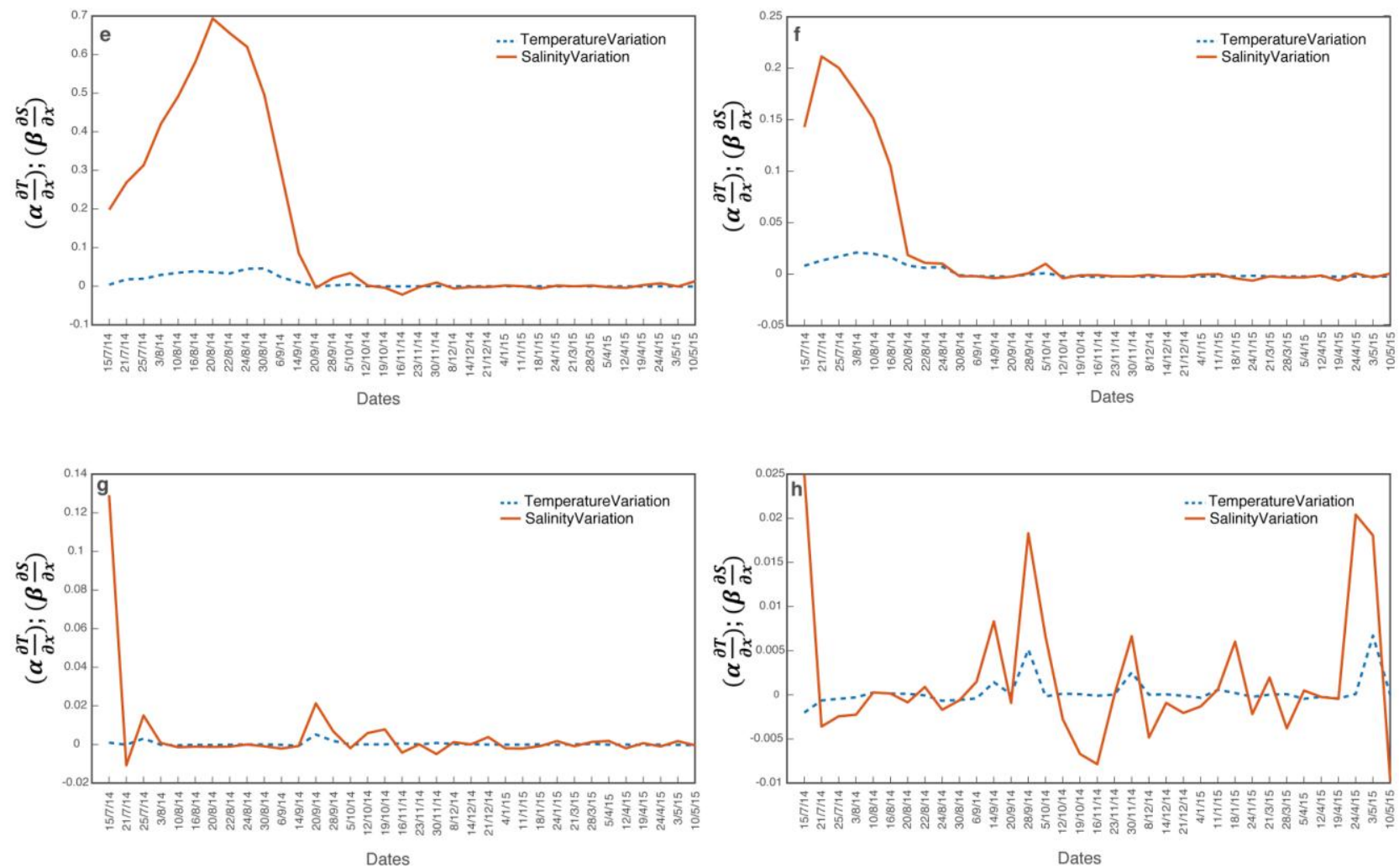

221 Figure 3. Stability analysis in terms of temperature $\left(\alpha \frac{\partial T}{\partial x}\right)$ and salinity $\left(\beta \frac{\partial S}{\partial x}\right)$ for a) 0.7, b) $\left.1.4, \mathrm{c}\right)$ 1.5 , d) 1.6 , e) 1.7, f) 1.8, g) 1.9 and h) $2.0 \mathrm{~m}$ from the bottom along first operation season in

Granada Solar Pond using the methodology described by Alenezi (2012).

Despite being a completely different methodology, the results reflect the same trend using the stability $\mathrm{E}$ analysis (Talley et al., 2011). However, the use of thermal and salinity expansion coefficients provides more detailed results. Figure $3 a$ shows the stability analysis using the expansion coefficients for depth $0.7 \mathrm{~m}$ from bottom, as can be seen the salinity gradient is higher than temperature gradient for most of 229 the operation period confirming the stability condition defined by Eq. 7. It is also observed that at the end of this operation period some instabilities and an almost neutral condition was reported at the bottom of the NCZ. The instabilities are clearly detected at each depth and also seen as progressively occur as they are transmitted from the upper layers. as can be seen in Figures 3b-3h. 
233 Clearly, the main problem of the system started in the layer located at $2 \mathrm{~m}$ from the bottom (Figure $3 \mathrm{~h}$ ),

234 where the temperature gradient is sometimes higher than the salinity; hence, the stability is not satisfied.

235 This irregular profile may be caused by the environmental conditions that affect the UCZ and later it is 236 transmitted to the NCZ. This irregular profile detected in the upper layers of the NCZ is slowly transmitted 237 (it took five months) through the NCZ until the layer located at $1.4 \mathrm{~m}$ from the bottom (Figure $3 \mathrm{~b}$ ). Additionally, this analysis also confirms a gradient degradation from the lowest part of the NCZ, detected at the end of the operation season at $0.7 \mathrm{~m}$ from the bottom.

240 The degradation in the highest layers of the NCZ may be consequence of the environmental conditions that affect the UCZ and inevitable are transmitted to the lower layers. However, identifying the cause for which the gradient begins to degrade from the bottom is more complex. This degradation can be a consequence of the different processes that take place at the boundary of the NCZ and the LCZ, the heat extractions, the addition of salt through the charger, among others; It can be proposed as a hypothesis that it is a combination of effects, including the impact of the degradation of the gradient in the upper layers.

\subsection{Second operation season (2015)}

248 As in the previous case, two different methodologies are used to have a deep view of the evolution of stability during the second season of operation of the Granada solar pond. Although the system was operated for a longer period, compared to the first season, some problems were detected in the gradient at the NCZ in April 2016 and some parameters, such as density, were not recorded from this moment.

252 The stability profile evolution along the second operation season obtained using the methodology 253 described by Talley et al. (2011) is shown in Figure 4. 


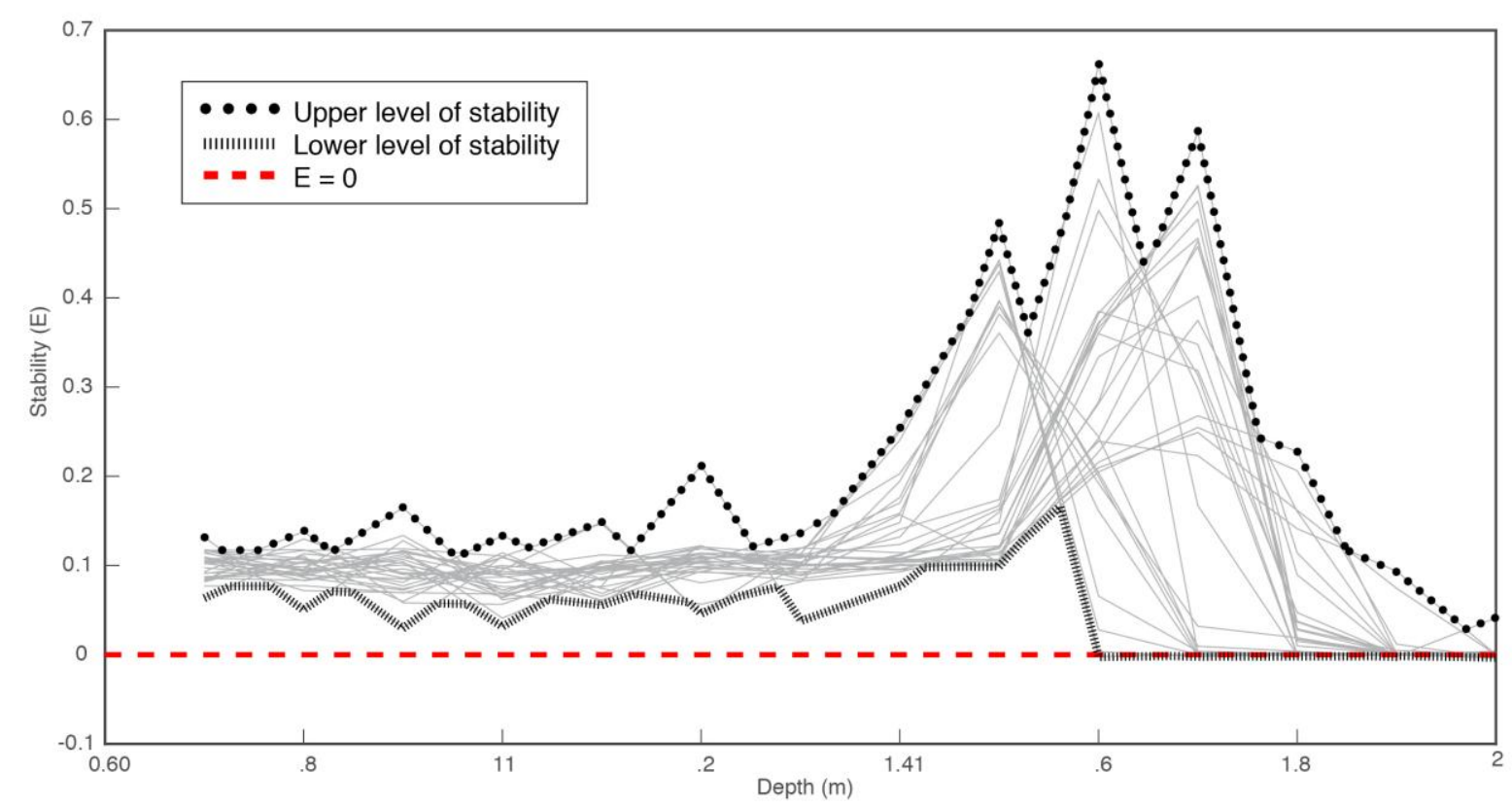

254

255 Figure 4. Variation of the Stability profile $(E)$ as a function of solar pond depth $(m)$ (from the 256 bottom) along the second operation season (2015) in Granada solar pond using the methodology 257 described by Talley et al. (2011).

258 In this case, stability problems are identified from the layer at $1.6 \mathrm{~m}$ to the layer at $2 \mathrm{~m}$ from the bottom. It 259 can be seen that in this case, the lower layers of the NCZ showed no tendency to degradation. Figure 5 260 depicts the same information than Figure 4, but in this case the evolution of the stability of each layer 261 along the operation season is identified. 


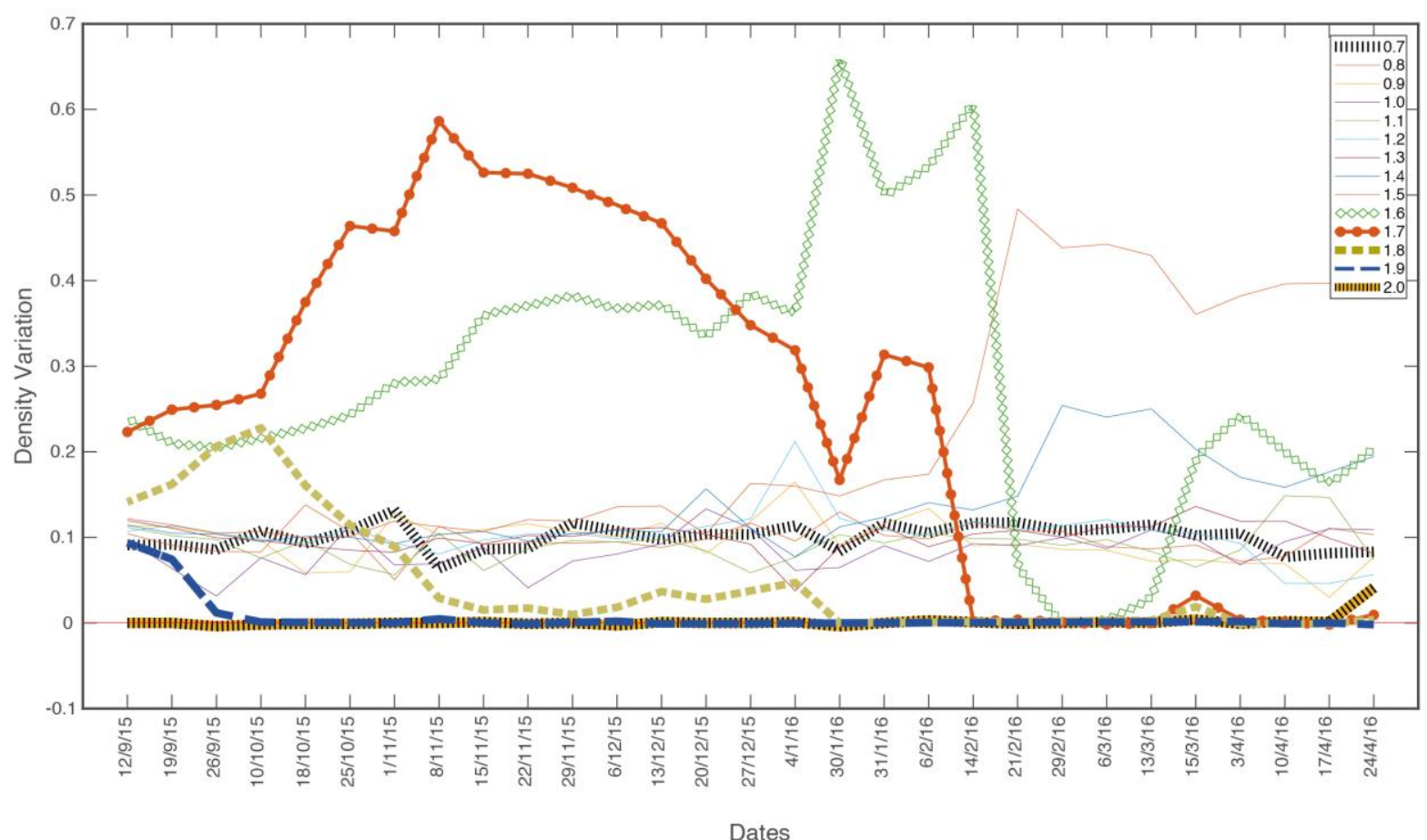

Figure 5. Stability evolution for different solar pond depth $(\mathrm{m})$ from the bottom along first operation season (2015) in Granada Solar Pond using the methodology described by Talley et al. (2011).

Throughout the second season of operation, a pattern similar to the first season is identified. The layer located at $2 \mathrm{~m}$ from the bottom was clearly unstable since the beginning of the operation season. This instability was transmitted to the lower layers throughout the operation season. On 10th October 2015 the layer located at $1.9 \mathrm{~m}$ from the bottom became neutral. Three months later, on $30^{\text {th }}$ January 2016 , the neutral condition reached at $1.8 \mathrm{~m}$ from the bottom. Few days later, on $14^{\text {th }}$ February 2016, the same situation is identified in the layer located at $1.7 \mathrm{~m}$ from the bottom. At the end of February also the layer located at $1.6 \mathrm{~m}$ from the bottom become neutral. However, this layer was able to recover the neutral situation as can be seen in Figure 5. The methodology proposed by Alenezi (2012) was also used to assess the second operation (Figure 6), the results obtained followed the same trend as for the first operation season. It is worth to be mentioned that although a larger amount of heat was extracted from the system in the second operation season, the NCZ was not degraded from the bottom as was observed in the first operation season. 

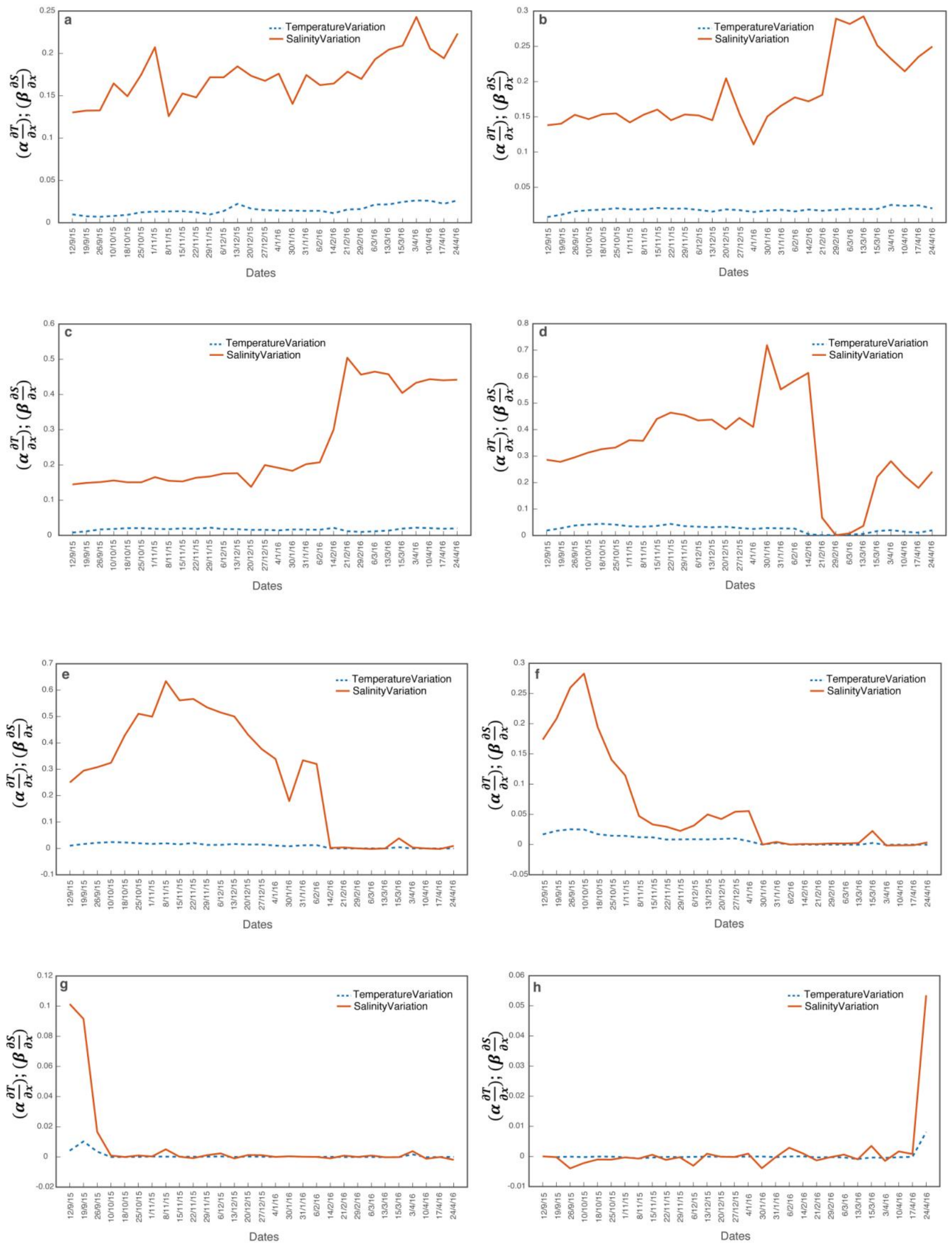
Figure 6. Stability analysis in terms of temperature $\left(\alpha \frac{\partial T}{\partial x}\right)$ and salinity $\left(\beta \frac{\partial S}{\partial x}\right)$ for a) 0.7, b) $\left.1.4, \mathrm{c}\right)$

\section{Conclusions}

285

286

The salinity gradient stability can be affected by the environmental and operational parameters. This note evaluates the stability of the Granada solar pond during two seasons of operation that reported a degradation of the salinity gradient. Two methodologies based on the principle of stratification were used to assess the data collected during two seasons of operation. Results indicate that boundaries of the gradient UCZ-NCZ and NCZ-LCZ are the main source of instability. This irregular profile may be caused by the environmental conditions affecting the UCZ and then transmitted to the NCZ, while the cause of degradation in bottom is more complex and can be connected with operational processes of the pond. For first operation period, the neutral situation began at $2 \mathrm{~m}$ from the bottom and needed about a month to be detected in the layer immediately below and five months at $1.4 \mathrm{~m}$ from the bottom. Otherwise, according to the expansions coefficients, the salinity gradient was higher than temperature gradient for most of the operation period at $0.7 \mathrm{~m}$ from the bottom confirming the stability condition. For second period, the same trend was observed, the layer located at $2 \mathrm{~m}$ from the bottom is clearly unstable since the beginning of the operation season, however, in this case, the instability only reached a depth of $1.6 \mathrm{~m}$ from the bottom and no degradation was observed from the bottom of the NCZ.

The methodology employed in this study can be successfully used in the control of the salinity gradient in the Granada solar pond since it provides information on how the degradation evolves once it has occurred, as has been seen in both seasons of operation that followed the same trends. It is worth mentioning that both methodologies showed the same results, however, the methodology based on the 

interests in terms of operation of solar pond technology.

305

306

307

308

309 


\section{Appendix 1. Expansion coefficients}

2 Both thermal $(\mathrm{T})$ and salinity $(\mathrm{S})$ gradients depend on density, pressure and temperature or salinity,

3 respectively. Hence, these parameters are not constant neither along the system nor along the time, in

4 other words, each point of the system at each time has a different value of these coefficients.

5 Thus, the coefficients of thermal $(\alpha)$ and salinity $(\beta)$ expansion are determined through Eqs. A1 and A2

6 (Lillibridge, 1989):

$$
\begin{aligned}
& \alpha=-\left(\frac{1}{\rho}\right) \frac{\partial \rho}{\partial T}=-\left(\frac{1}{\rho}\right)\left(\frac{\frac{\partial \rho_{o}}{\partial T}}{1-\frac{P}{K}}-\rho_{0} P \frac{\frac{\partial K}{\partial T}}{(K-P) 2}\right) \\
& \beta=-\left(\frac{1}{\rho}\right) \frac{\partial \rho}{\partial S}=-\left(\frac{1}{\rho}\right)\left(\frac{\frac{\partial \rho_{o}}{\partial S}}{1-\frac{P}{K}}-\rho_{0} P \frac{\frac{\partial K}{\partial S}}{(K-P) 2}\right)
\end{aligned}
$$

7 where, $\rho_{o}$ and $\rho$ are the surface and subsurface density, respectively; $\mathrm{K}$ is compressibility; $P$ is the

8 pressure of the water layer; $T$ is temperature and $S$ is salinity. Figure A1 provides a global and 9 schematic overview of the procedure used to determine the expansion coefficients.

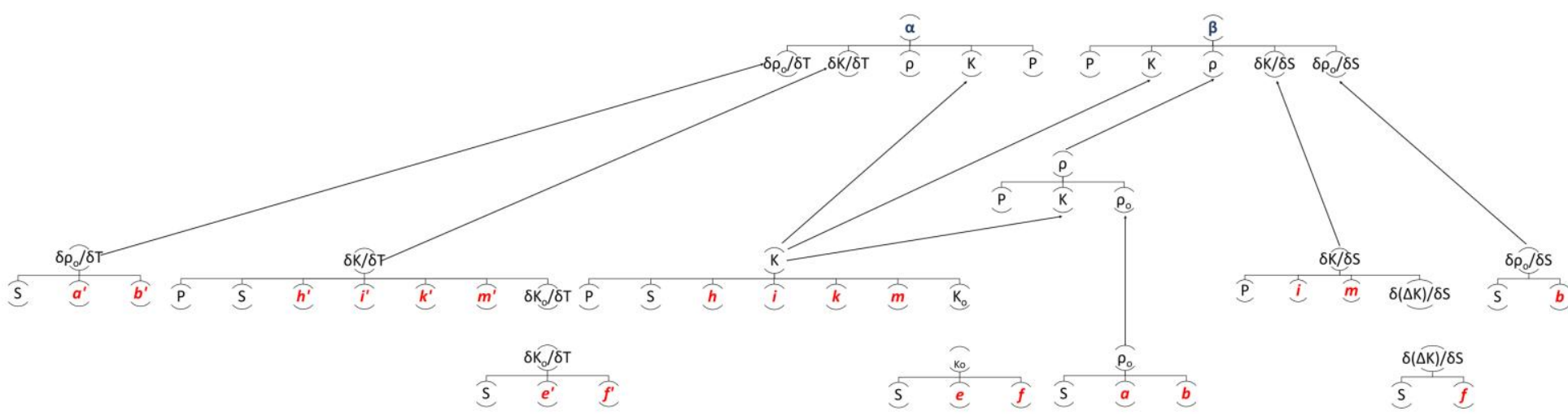

12 Figure A1. Schema of the methodology used to determine the expansion coefficients 
1 Accordingly, seven terms needed to be calculated: $\rho, \rho_{o}, K, \frac{\partial \rho_{o}}{\partial T}, \frac{\partial \rho_{O}}{\partial S}, \frac{\partial K}{\partial T}$ and $\frac{\partial K}{\partial S}$. The pressure, $\frac{\partial K}{\partial S}$, of

2 each layer is considered an input parameter. The pressure on solar pond surface can be assumed

3 equal to the atmospheric pressure and the pressure in each layer is the sum of the atmospheric

$4 \quad$ pressure and the pressure caused by the upper layers.

5 The equations needed to calculate the derivations $\left(\frac{\partial \rho_{o}}{\partial T}, \frac{\partial \rho_{o}}{\partial S}, \frac{\partial K}{\partial T}\right.$ and $\left.\frac{\partial K}{\partial S}\right)$ and parameters are presented

6 below. When a coefficient appears in the equations, marked in red, it means that it will be tabulated

7 specifically at the end of this section. To estimate the density, first, the surface density $\left(\rho_{o}\right)$ needs to be

8 determined:

$\rho_{0}(T, S)=\rho_{w}(T)+\Delta \rho(T, S)$

$9 \rho_{w}(T)$ and $\Delta \rho(T, S)$ may be obtained using the polynomial expressions A4 and 5 , respectively:

$\rho_{w}(T)=\sum_{i=0}^{5} a(i) T^{i}$

$\Delta \rho(T, S)=\sum_{j=2}^{4} S^{\frac{j}{2}} \sum_{i=0}^{n(j)} b(i, j) T^{i}$

10 Thus, the surface density $\left(\rho_{0}(T, S)\right)$ may be expressed in only one equation as describes Eq. A6:

$\rho_{0}(T, S)=\sum_{i=0}^{5} a(i) T^{i}+\sum_{j=2}^{4} S^{\frac{j}{2}} \sum_{i=0}^{n(j)} b(i, j) T^{i}$

11 The subsurface densities are calculated using the surface densities values, $\rho_{o}$, the pressure of the

12 water layer, $P$, and the compressibility, $K$ as describes Eq. A7: 


$$
\rho(T, S)=\frac{\rho_{0}(T, S)+1000 \frac{P}{K}}{1-\frac{P}{K}}
$$

1 The bulk modulus of compressibility, $K$, depends on $P, T$, and $S$. Its dependence on $P$ is reported in 2 the Eq. A8:

$$
K(P, T, S)=K_{0}(T, S)+P A(T, S)+P^{2} B(T, S)
$$

3 The terms $K_{o}, A$ and $B$, may be expressed in polynomial equations as $\rho_{o}$ as described by Eqs. A94 A11:

$$
\begin{aligned}
& K_{0}(T, S)=\sum_{i=0}^{4} e(i) T^{i}+\sum_{j=2}^{3} S^{\frac{j}{2}} \sum_{i=0}^{n(j)} f(i, j) T^{i} \\
& A(T, S)=\sum_{i=0}^{3} h(i) T^{i}+\sum_{j=2}^{3} S^{\frac{j}{2}} \sum_{i=0}^{n(j)} i(i, j) T^{i} \\
& B(T, S)=\sum_{i=0}^{2} k(i) T^{i}+\sum_{j=2}^{2} S^{\frac{j}{2}} \sum_{i=0}^{n(j)} m(i, j) T^{i}
\end{aligned}
$$

5 The general equations of $\alpha$ and $\beta$ include some derivatives, $\frac{\partial \rho_{o}}{\partial T}, \frac{\partial \rho_{O}}{\partial S}, \frac{\partial K}{\partial T}$ and $\frac{\partial K}{\partial S}$, the main advantage 6 of this method is that equation A11 can be relatively easy derived.

7 Thus, utilizing the notation $a^{\prime}(i)=i a(i)$, the following set of equations (A12-A16) contains 8 derivatives of the previous parameters depending on temperature.

$$
\frac{\partial \rho_{0}}{\partial T}=\sum_{i=0}^{5} a^{\prime}(i) T^{i-1}+\sum_{j=2}^{4} S^{\frac{j}{2}} \sum_{i=0}^{n(j)} b^{\prime}(i, j) T^{i-1}
$$




$$
\frac{\partial K}{\partial T}=\frac{\partial K_{0}}{\partial T}+P \frac{\partial A}{\partial T}+P^{2} \frac{\partial B}{\partial T}
$$

1 Where,

$$
\begin{aligned}
& \frac{\partial K_{0}}{\partial T}=\sum_{i=0}^{4} e^{\prime}(i) T^{i-1}+\sum_{j=2}^{3} S^{\frac{j}{2}} \sum_{i=0}^{n(j)} f^{\prime}(i, j) T^{i-1} \\
& \frac{\partial A}{\partial T}=\sum_{i=0}^{3} h^{\prime}(i) T^{i-1}+\sum_{j=2}^{3} S^{\frac{j}{2}} \sum_{i=0}^{n(j)} i^{\prime}(i, j) T^{i-1} \\
& \frac{\partial B}{\partial T}=\sum_{i=0}^{2} k^{\prime}(i) T^{i-1}+\sum_{j=2}^{2} S^{\frac{j}{2}} \sum_{i=0}^{n(j)} m^{\prime}(i, j) T^{i-1}
\end{aligned}
$$

2 Finally, the same parameters need to be derivative depending on salinity, $\left(\frac{\partial \rho_{o}}{\partial S}\right.$ and $\left.\frac{\partial K}{\partial S}\right)$. These

3 parameters may be determined using the equations $A 17$ and $A 18$ :

$$
\begin{aligned}
& \frac{\partial \rho_{0}}{\partial S}=\sum_{j=2}^{4} S^{\frac{j}{2}-1} \sum_{i=0}^{n(j)} b(i, j) T^{i} \\
& \frac{\partial K}{\partial S}=\frac{\partial(\Delta K)}{\partial T}+P \frac{\partial(\Delta A)}{\partial T}+P^{2} \frac{\partial(\Delta B)}{\partial T}
\end{aligned}
$$

4 The parameters required to determine $\frac{\partial K}{\partial T}$ can be obtained using the equations (A19-A21), which are 5 the derivatives of the initials but, in this case, depending on salinity.

$$
\begin{aligned}
& \frac{\partial(\Delta K)}{\partial S}=\sum_{j=2}^{3} \frac{j}{2} S^{\frac{j}{2}-1} \sum_{i=0}^{n(j)} f(i, j) T^{i} \\
& \frac{\partial(\Delta A)}{\partial S}=\sum_{j=2}^{3} \frac{j}{2} S^{\frac{j}{2}-1} \sum_{i=0}^{n(j)} i(i, j) T^{i}
\end{aligned}
$$




$$
\frac{\partial(\Delta B)}{\partial S}=\sum_{j=2}^{2} \frac{j}{2} S^{\frac{j}{2}-1} \sum_{i=0}^{n(j)} m(i, j) T^{i}
$$

1 All coefficients included in equations A12-A21, marked in red color, are reported in Table A1:

2 Table A1. Coefficients used to determine the thermal and saline expansion coefficients, $\alpha$ and $\beta$.

$$
\begin{aligned}
& \begin{array}{llllll}
T^{0} & T^{1} & T^{2} & T^{3} & T^{4} & T^{5}
\end{array}
\end{aligned}
$$

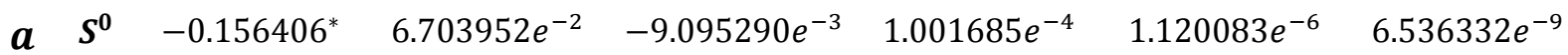

$$
\begin{aligned}
& \text { b } \begin{array}{llllll}
\boldsymbol{S}^{1} & 8.24493 e^{-1} & -4.0899 e^{-3} & 7.6438 e^{-5} & -8.2467 e^{-7} & 5.3875 e^{-9}
\end{array} \\
& S^{\frac{3}{2}} \quad-5.72466 e^{-3} \quad 1.0227 e^{-4} \quad-1.6546 e^{-6} \\
& S^{2} \quad 4.8314 e^{-3} \\
& \begin{array}{lllllll}
\boldsymbol{e} & \boldsymbol{S}^{\mathbf{0}} & 19652.21 & 148.4206 & -2.327105 & 1.360477 e^{-2} & -5.155288 e^{-5}
\end{array} \\
& \text { f } \boldsymbol{S}^{\mathbf{1}} \quad 54.6746 \quad-0.603459 \quad 1.09987 e^{-2} \quad-6.167 e^{-5} \\
& S^{\frac{3}{2}} \quad 7.944 e^{-2} \quad 1.6483 e^{-2} \quad-5.3009 e^{-4}
\end{aligned}
$$

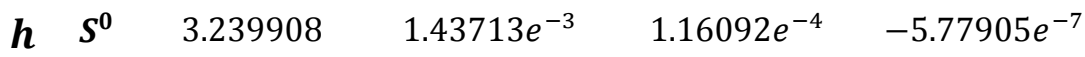

$$
\begin{aligned}
& \begin{array}{lllll}
\boldsymbol{i} & \boldsymbol{S}^{\mathbf{1}} & 2.2838 e^{-3} & -1.0981 e^{-5} & 1.16078 e^{-6}
\end{array} \\
& S^{\frac{3}{2}} \quad 1.1910754 \\
& \begin{array}{lllll}
\boldsymbol{k} & \boldsymbol{S}^{\mathbf{0}} & 8.50935 e^{-5} & -6.12293 e^{-6} & 5.2787 e^{-8}
\end{array} \\
& \boldsymbol{m} \boldsymbol{S}^{\mathbf{1}} \quad-9.9348 e^{-7} \quad 2.0816 e^{-8} \quad 9.1697 e^{-10}
\end{aligned}
$$

\section{$4 \quad$ Acknowledgments}

5 The authors gratefully acknowledge personnel from Solvay Minerales and Solvay Martorell facilities for

6 practical assistance, especially to M. Gonzalez, C. Gonzalez, C. Aladjem, J.L. Ochando and M. 
1 Giménez for their valuable cooperation. This research was financially supported by the Spanish Ministry

2 of Science and Innovation (WASTE2PRODUCT project) and the Catalan Government (Project Ref.

3

4

5

\section{5. References}

7 Alcaraz, A., Valderrama, C., Cortina, J. L., Akbarzadeh, A., Farran A., 2016. Enhancing the efficiency of solar 2017SGR312).

Alcaraz, A., Montalà, M., Cortina, J.L., Akbarzadeh, A., Aladjem, C., Farran, A., Valderrama, C., 2018a. Design, construction, and operation of the first industrial salinity-gradient solar pond in Europe: An efficiency analysis perspective. Sol. Energy 164, 316-326.

Alcaraz, A., Montalà, M., Valderrama, C., Cortina, J.L., Akbarzadeh, C., Farran, A. 2018b. Thermal performance of $500 \mathrm{~m} 2$ salinity gradient solar pond in Granada, Spain under strong weather conditions. Solar Energ 171, 223228

Alcaraz, A., Montalà, M., Valderrama, C., Cortina, J.L., Akbarzadeh, C., Farran, A. 2018c. Increasing the storage capacity of a solar pond by using solar thermal collectors: Heat extraction and heat supply processes using inpond heat exchangers. Solar Energy 171, 112-121

Alenezi, I., 2012. Salinity gradient solar ponds: Theoretical modelling and integration with desalination. PQDT UK Irel. https://doi.org/May, 2012

Bernad, F., Casas, S., Gibert, O., Akbarzadeh, A., Cortina, J.L., Valderrama, C. 2013. Salinity gradient solar pond: Validation and simulation model. Sol. Energy 98, 366-374. doi:10.1016/j.solener.2013.10.004

El Mansouri, A., Hasnaouia, M.,.Amahmid, A., Bennacer, R., 2018. Transient modeling of a salt gradient solar pond using a hybrid Finite-Volume and Cascaded Lattice-Boltzmann method: Thermal characteristics and stability analysis. Energy Conversion and Management 158, 416-429

Ganguly, S., Date, A., Akbarzadeh, A. 2018a. Investigation of thermal performance of a solar pond with external heat addition. Journal of Solar Energy Engineering 140, 024501-024506.

Ganguly, S., Date, A., Akbarzadeh, A. 2018b. Effectiveness of bottom insulation of a salinity gradient solar pond. 
Husain. M., Sharma, G., Samdarshi, S.K., 2012. Innovative design of non-convective zone of salt gradient solar pond for optimum thermal performance and stability. Applied Energy 93 (2012) 357-363

Kumar, A., Singh, K., Verma, S., Das, R. 2018. Inverse prediction and optimization analysis of a solar pond powering a thermoelectric generator. Solar Energy 169, 658-672.

Leblanc, J., Akbarzadeh, A., Andrews, J., Lu, H., Golding, P., 2011. Heat extraction methods from salinitygradient solar ponds and introduction of a novel system of heat extraction for improved efficiency. Sol. Energy. https://doi.org/10.1016/j.solener.2010.06.005

Lillibridge III, J.L., 1989. Computing the Seawater Expansion Coefficients Directly from the 1980 Equation of State. J. Atmos. Ocean. Technol. 6, 59-66.

Liu, H., Jiang, L., Wu, D., Sun, W., 2015. Experiment and simulation study of a trapezoidal salt gradient solar pond. Sol. Energy 122, 1225-1234. https://doi.org/10.1016/j.solener.2015.09.006

Lu, H., Swift, A.H.P., Hein, H.D., Walton, J.C., 2004. Advancements in Salinity Gradient Solar Pond Technology Based on Sixteen Years of Operational Experience. J. Sol. Energy Eng. 126, 759. https://doi.org/10.1115/1.1667977

Ouni, M., Guizani, A., Lu, H., Belghith, A., 2003. Simulation of the control of a salt gradient solar pond in the south of Tunisia. Sol. Energy 75, 95-101. https://doi.org/10.1016/j.solener.2003.07.011

Talley, L.D., Pickard, G.L., Emery, W.J., Swift, J.H., 2011. Descriptive physical oceanography: An introduction: Sixth edition, Descriptive Physical Oceanography: An Introduction: Sixth Edition. https://doi.org/10.1016/C2009-0-24322-4

Valderrama, C., Gibert, O., Arcal, J., Solano, P., Akbarzadeh, A., Larrotcha, E., Cortina, J.L., 2011. Solar energy storage by salinity gradient solar pond: Pilot plant construction and gradient control. Desalination $279,445-$ 450. doi:10.1016/j.desal.2011.06.035

Valderrama, C., Luis Cortina, J., Akbarzadeh, A., 2016. Solar Ponds, in: Storing Energy: With Special Reference to Renewable Energy Sources. pp. 273-289. doi:10.1016/B978-0-12-803440-8.00014-2

Xu, H., Nielsen, C.E., Golding, P., 1987. Prediction of Internal Stability within a Salinity Gradient Solar Pond. Proc. Conf. Int. Prog. olar Ponds.

Zangrando, F., 1980. A simple method to establish salt gradient solar ponds. Sol. Energy 25, 467-470. doi:10.1016/0038-092X(80)90456-9 